\title{
Exposure to Secondhand Smoke in the Home and Public areas among Adolescents in Abuja, Nigeria: Tobacco control implications
}

\author{
Uyoyo Omaduvie ${ }^{1}$, Akinyele Adisa ${ }^{2}$
}

\begin{abstract}
INTRODUction Secondhand smoke (SHS) causes death and disease among non-smokers. In 2008, the Nigerian Federal Capital Territory, Abuja, passed a comprehensive smoke-free law. This study assessed the baseline prevalence of SHS exposure in the home and at public areas among secondary school students in Abuja, Nigeria during 2008.

мeтHods The 2008 Global Youth Tobacco Survey dataset was analysed for 1399 students in Abuja. Prevalence of support for smoke-free laws in public places as well as of exposure to SHS in the home and at non-home areas (including public spaces) was calculated overall, as well as by population subgroups. Chi-squared test was used to assess statistical significance of within-group differences. Multivariate logistic regression was used to assess significant correlates of SHS exposure and support for smoke-free laws. All analyses were 2 -tailed and the level of significance was set at $\mathrm{P}<0.05$. RESULTS Overall prevalence of SHS exposure in the home was $24.1 \%$ (95\%CI: 21.1-27.1) while the prevalence of SHS exposure in non-home areas, including public spaces was 43.0\% (95\%CI: 36.6-49.4). The odds of exposure to SHS were significantly higher among current smokers as well as students that had 1 close friend that smoked. Overall, $55.3 \%$ of students supported smoke-free policies in public places.

ConcLusions This study showed that a substantial proportion of adolescents in Abuja were exposed to SHS in public places in 2008. Monitoring and evaluation of existing smoke-free policies will provide evidence base for strengthening existing measures or introducing new evidence-based interventions to help reduce youth SHS exposure.
\end{abstract}

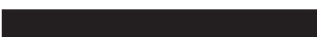 \\ AFFILIATION \\ 1 Department of Medicine \\ and Surgery, College of \\ Medicine, University of \\ Ibadan, Ibadan, Nigeria \\ 2 Department of Oral \\ pathology, College of \\ Medicine, University of \\ Ibadan, Ibadan, Nigeria \\ CORRESPONDENCE TO \\ Dr. Omaduvie, Department \\ of Medicine, College of \\ Medicine, University of \\ Ibadan, Nigeria. Phone: \\ 404-576-2719; \\ email: uyoyo.omaduvie@ \\ gmail.com

\section{KEY WORDS} \\ compliance, smoking, \\ secondhand smoke, policy, \\ tobacco control
}

\section{INTRODUCTION}

Exposure to secondhand smoke (SHS) is a serious threat to public health and causes death and disease in nonsmoking adults and children ${ }^{1}$. The U.S. Surgeon General's report on SHS concluded that there is no risk-free level of SHS exposure, and even brief exposures can cause disease in otherwise healthy people, or exacerbate conditions in people with pre-existing disease ${ }^{1}$. Children are particularly vulnerable to the effects of SHS exposure due to their higher metabolism and ventilation rates, as well as being less able to control their exposure to SHS compared to adults 2 . The elimination of smoking in all indoor areas is the only effective way to fully protect nonsmokers from SHS exposure in indoor environments. Smoke-free legislations are dependent on political will, enforcement and societal support. However, while the public may be supportive of smoke-free legislation, adherence may decline rapidly if enforcement is limited or non-existent. In 2008, the Nigerian Federal Capital Territory (FCT), Abuja, passed the most comprehensive public smoking ban yet seen in the country. This ban outlawed smoking in all communal areas including restaurants, bars and workplaces ${ }^{3}$. In May 2015, the national tobacco control bill was signed into law. This new tobacco control law provides new opportunities for broad scale reductions in SHS exposure in public places among youths at a national level. The law prohibits smoking in public areas ${ }^{4}$. However, to date, very little information exists on Nigerian youth exposure to SHS in public areas. The Global Youth Tobacco Survey (GYTS) provides a reliable and valid surveillance mechanism to monitor the effectiveness of the tobacco control efforts in Nigeria aimed at reducing SHS exposure among youth. The objective of this study therefore was to provide the baseline prevalence of exposure to SHS in the home and in public areas in 2008. Subsequent waves of the GYTS in Nigeria ${ }^{5}$, will provide follow-up data to assess 
the effectiveness of regional and national policies in reducing SHS exposure in public places among youths. Such studies will provide evidence base to strengthen existing policies and implement new tobacco control measures that encourage smokers to quit, reduce exposure to SHS and discourage youths from initiating tobacco use.

\section{METHODS}

\section{Study Background}

The GYTS is a school-based survey that monitors tobacco use, attitudes about tobacco use, and exposure to secondhand smoke (SHS) among junior and senior secondary school students every four years ${ }^{3}$. The most recent wave of the GYTS in Nigeria was conducted in 2008 in FCT Abuja, Cross River State, as well as three cities: Ibadan, Lagos, and Kano. For this analysis, regional data from FCT Abuja was used.

\section{Sampling Procedures}

Students were sampled in the 2008 Nigeria GYTS in a two-stage cluster sample design. At the first sampling stage, schools were selected in proportion to the number of students enrolled in the selected classes. At the second stage, classes within the selected schools were randomly selected. All students attending school in the selected classes on the day the survey was administered were eligible to participate. In total, 1399 students were selected from 20 schools in Abuja in 2008, yielding a student participation rate of $89.2 \%$. Data were weighted to adjust for non-response and yield regionally representative estimates.

\section{Measures and Definitions}

\section{Exposure to SHS in the Home and public spaces}

This was assessed using the question: "During the past 7 days, on how many days have people smoked in your home, in your presence?" Respondents who indicated any option other than "0 days" were classified as being exposed to SHS in the home. Exposure to SHS in public spaces was assessed using the question: "During the past 7 days, on how many days have people smoked in your presence, in places other than in your home?" Respondents who indicated any option other than "0 days" were classified as being exposed to SHS in public spaces.

\section{Support of smoke-free policies in public places}

This was defined as a "Yes" response to the question: "Are you in favor of banning smoking in public places (such as in restaurants; buses, taxis, trains and airplanes; in schools, hospitals; on playgrounds, airport waiting halls, and sports arenas and in clubs)?" Perception about harm from Smoking and passive smoking

Perception that smoking and passive smoking are harmful was defined as a "Probably Yes" or "Definitely Yes" response to the respective questions: "Do you think cigarette smoking is harmful to your health?", "Do you think the smoke from other people's cigarettes is harmful to you?"

Respondents' disposition towards Smokers and SHS Exposure was assessed using the question: "If someone asks your permission to smoke around you, do you let them?" Categorical responses were "Yes" or "No".

\section{Tobacco Use}

Current smoking was defined as smoking cigarettes on 1 day within the past 30 days. Current smokers were also asked where they usually smoked. Categorical options included "At home", "at school", "at work", "at a friends" houses, or "at social events". Current smokeless tobacco use was defined as a "Yes" response to the question: "During the past 30 days (one month), did you use any form of smokeless tobacco products (e.g. chewing tobacco, snuff, dip)?"

Parental smoking was defined as any response other than "none" to the question: "Do your parents smoke?" Peer smoking was defined as any response other than "none" to the question: "Do any of your closest friends smoke cigarettes?" Responses of "don't know" were excluded.

\section{Socio-demographic Characteristics}

These included age ( $\varsigma 12 ; 13-14 ; 15-16$; or 17 years); sex (boy or girl); and school level (junior or senior secondary school levels).

\section{Statistical Analysis}

Data were weighted to account for the complex survey design and analyzed with Stata V12. Descriptive statistics (percentages) were used to summarize the distribution of the study population by age, sex, school level, current cigarette and smokeless tobacco use as well as parental and peer smoking status. The proportion of students in support of smoke-free policies in public places as well those exposed to SHS in the home and in non-home areas including public spaces, were calculated overall, as well as by socio-demographic and tobacco use characteristics. A 2-sided chi square test was used to assess statistical significance of within-group differences $(\mathrm{P}<0.05)$. Logistic regression analysis was used to determine correlates of exposure to SHS in public areas assessing for age, sex, school level, tobacco use status, as well as parental and peer cigarette use status. All analyses were two-tailed and the level of significance was set at the $5 \%$ alpha level. 


\section{RESULTS}

Girls comprised $47.8 \%$ of the study population, while $52.2 \%$ were boys. About $63.1 \%$ of all students were in junior secondary, while $37 \%$ where in senior secondary school. Approximately $11.7 \%$ were current users of smokeless tobacco while $4.2 \%$ currently smoked cigarettes. Other participant characteristics are shown in Table 1.

About 1 out of every 4 (24.1\%; 95\%CI: 21.1-27.1) students was exposed to SHS in the home. Prevalence was higher among boys compared to girls ( $28.8 \%$ vs. $17.2 \%$ respectively; $\mathrm{P}<0.05)$; among current smokers compared to non-smokers (75.4 vs. 20.6 respectively; $\mathrm{P}<0.05$ ), as well as among respondents with 1 smoking parent compared to those with no smoking parent $(57.5 \%$ vs. $21.0 \%$ respectively; $\mathrm{P}<0.05)$. Students with 1 friend that smoked also had a higher prevalence of exposure to SHS in the home (47.1\%) compared to those with no close friend that smoked (19.0\%) $(\mathrm{P}<0.05)$ About $43.0 \%$ (95\%CI: 36.6-49.4) of all students were exposed to SHS in non-home areas including public spaces (Table 2). Prevalence was higher among current smokers compared to non-smokers (77.7\% vs. $40.8 \%$ respectively; $\mathrm{P}<0.05$ ). Similarly, respondents with 1 close friend that smoked had a higher prevalence of exposure $(60.6 \%)$ compared to those with no smoking friends $(39.2 \%)(\mathrm{P}<0.05)$. After adjusting for potential confounders, current smoking and having friends that smoked were the only significant predictors of exposure to SHS in non-home areas including public spaces (Table 3). Overall prevalence of support for bans on smoking in public places was about 55.3\% (95\%CI: 44.8-65.8). Furthermore, $73.9 \%$ (95\%CI: 67.2-80.6) of all students believed that cigarette smoking was harmful while $63.5 \%$ (95\%CI: 56.6-70.4) believed that passive smoking was harmful. Among current smokers, about $38.1 \%$ reported smoking at home; $14.1 \%$ reported smoking at friend's houses whereas close to half of current smokers $(47.8 \%)$ reported smoking in public areas such as school, work, social events, and other spaces such as parks and shopping centers. Among non-smokers, 89.7\% (95\%CI: 87.5-92.0) stated that they would not allow someone to smoke around them.

Table 1: Characteristics of study participants, Global Youth Tobacco Survey, Abuja Nigeria, 2008

\begin{tabular}{|c|c|c|}
\hline Characteristic & $n$ & $\%$ \\
\hline \multicolumn{3}{|c|}{ Age, years } \\
\hline$<12$ & 407 & 26.9 \\
\hline $13-14$ & $13-14$ & 25.5 \\
\hline $13-14$ & 418 & 34.2 \\
\hline$\geq 17$ & 148 & 13.5 \\
\hline \multicolumn{3}{|c|}{ Sex } \\
\hline Girl & 648 & $\operatorname{Sex}$ \\
\hline Boy & 626 & 52.2 \\
\hline \multicolumn{3}{|c|}{ School level } \\
\hline Junior Secondary School & 977 & 63.1 \\
\hline Senior Secondary School & 328 & 37 \\
\hline \multicolumn{3}{|c|}{ Current smoking status } \\
\hline Non-smoker & 1234 & 95.8 \\
\hline Smoker & 55 & 4.2 \\
\hline \multicolumn{3}{|c|}{ Current Smokeless tobacco use status } \\
\hline Non-user & 1,192 & 88.3 \\
\hline User & 165 & 11.7 \\
\hline \multicolumn{3}{|c|}{ Parental smoking } \\
\hline None & 1,202 & 92.6 \\
\hline$\geq 1$ parent smokes & 104 & 7.4 \\
\hline \multicolumn{3}{|c|}{ Peer smoking } \\
\hline None & 1,137 & 81.2 \\
\hline$\geq 1$ close friend smokes & 250 & 18.9 \\
\hline
\end{tabular}


Table 2: Prevalence of Support for Smoke free laws, and exposure to Secondhand smoke in the home and in public places, Global Youth Tobacco Survey, Abuja Nigeria, 2008

Characteristic Insupport of smoking ban in public places Exposed to SIIS in the home Evposed to SIIS in non Ilome areas,
in cluding public spaces

Age, years

\begin{tabular}{|c|c|c|c|}
\hline$\leq 12$ & $53.5(41.1-65.8$ & $24.0(18.5-29.6$ & $44.5(37.6-51.5$ \\
\hline $13-14$ & $57.7(44.3-71.2)$ & $20.2(15.9-24.5)$ & $37.9(30.2-45.6)$ \\
\hline $15-16$ & $57.7(46.2-69.2)$ & $25.7(19.4-32)$ & $43.7(30.8-56.6$ \\
\hline$\geq 17$ & $54.3(33.6-75.1)$ & $26.8(14.1-39.5)$ & $44.3(39.7-48.8)$ \\
\hline \multicolumn{4}{|c|}{ Sex } \\
\hline Girl & $59.1(48.1-70)$ & $17.2(14.3-20.1)$ & $39(32.4-45.6)$ \\
\hline Boy & $53.5(41-66)$ & $28.8(25.5-32.2)$ & $45.9(38.9-52.9)$ \\
\hline \multicolumn{4}{|c|}{ School level } \\
\hline Junior Secondary School & $51.9(39.2-64.5$ & $22.5(18.3-26.6)$ & $38.7(30.2-47.2)$ \\
\hline Senior Secondary School & $61.4(45.5-77.4)$ & $26.3(19-33.6)$ & $46.5(34.1-58.9)$ \\
\hline
\end{tabular}

Current smoking status

Non-smoker

Smoker

Non-user

User

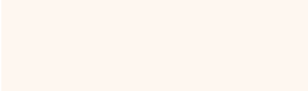

None

$\geq 1$ parent smokes
$55.6(43.9-67.3)$

$58.8(36.5-81.1)$

$56.5(45.8-67.2)$

$47.7(34.5-61)$

$56.4(45-67.9)$

$51.7(40.3-63.1)$

$55.3(43.8-66.8)$

$55.3(45.1-65.5)$

$55.3(44.8-65.8)$
$20.6(17.9-23.2)$

$75.4(63.6-87.2)$

Current Smokeless tobacco use status

$23.2(20.1-26.4)$

$34(26.1-41.9)$

Parental smoking

$21(17.6-24.3$

$57.5(42.9-72)$

Peer smoking

None

$\geq 1$ close friend smokes

Overall
$19(16.1-21.8)$

$39.2(33.5-44.8)$

$47.1(39-55.3)$

$60.6(50.1-71.1)$

$24.1(21.1-27.1)$
$43.5(37.1-49.8)$

$42.6(29.5-55.7)$

$41.6(34.8-48.5)$

$60(51.8-68.2)$ 
Table 3: Adjusted odds ratios for determinants of exposure to secondhand smoke in public places, Abuja, Nigeria, GYTS, 2008

\begin{tabular}{lc} 
Characteristic & aOR $\left(95^{\circ} \mathrm{CI}\right)$ \\
\multicolumn{1}{c}{ Age, years } \\
12 & 1.0 (Referent) \\
$13-14$ & $0.74(0.54-1.02)$ \\
$15-16$ & $0.77(0.52-1.15$ \\
$\geq 17$ & $0.51(0.35-0.77)$ \\
& Sex \\
Girl & 1.0 (Referent) \\
Boy & 1.08 (0.80-1.44
\end{tabular}

School level

$\begin{array}{lc}\begin{array}{l}\text { Junior Secondary School } \\ \text { Senior Secondary School } \\ \text { Current smoking status }\end{array} & 1.0 \text { (Referent) } \\ \text { Non-smoker } & 1.0 \text { (Referent) } \\ \text { Smoker } & 3.46(1.40-8.55)^{*} \\ & \text { Current Smokeless tobacco use status } \\ \text { Non-user } & 1.0 \text { (Referent) } \\ \text { User } & 0.71(0.45-1.13) \\ & 1.0 \text { (Referent) } \\ \text { None } & 1.48(0.95-2.33 \\ \geq 1 \text { parent smokes } & 1.0 \text { (Referent) } \\ & 1.99(1.26-3.15) *\end{array}$

*Statistically significant results $(p<0.05)$

\section{DISCUSSION}

These findings indicated that in 2008, about a fourth of all junior and senior secondary school students in Abuja were exposed to SHS in the home while over 2 out of every 5 students were exposed to SHS at non-home areas including public spaces. These findings, coupled with the fact that close to half of adolescent smokers reported smoking in public areas, indicate that a substantial proportion of youths were exposed to SHS in public spaces at baseline. This underscores the need for well funded, population based measures to reduce SHS exposure among youths. The effectiveness of the 2008 FCT Abuja smoke-free policy on reducing youth exposure to SHS may have a ripple effect on tobacco control efforts in Nigeria. For example, it may encourage the introduction of comprehensive smoke free laws in other states or local governments. Already, Lagos state has followed suit in proposing a comprehensive smoke-free policy prohibiting smoking in public areas, as well as banning smoking while driving ${ }^{6}$. The findings showed that $21 \%$ of adolescents with non-smoking parents stated that SHS was present in their home. This percentage is similar to the one $(19.2 \%)$ found by Victoria et al in Portugal ${ }^{7}$. This is an important finding which may promote home smoking

rule/precautions for cohabitants and guests and may endorse the "new" policy maker strategy which points at the non-smoker.

Enhanced and sustained efforts towards firm enforcement of policies already in place as well as implementation of stronger measures may help increase compliance and receptivity towards tobacco control policy in Nigeria ${ }^{8}$. In addition, while compliance with smoke-free laws has traditionally focused on smokers' behaviors, the fact that the majority of non-smokers in our study were unfavorably disposed towards allowing someone smoke around them may have some policy implications. Policy makers may invest in mass media campaigns that inform non-smokers of their rights and encourage them to report violations of smoke-free laws. Other evidence based measures that may help reduce prevalence and intensity of smoking as well as SHS exposure are outlined in the WHO's MPOWER package and include: raising tobacco taxes, warning about the dangers of tobacco use with hard-hitting anti-tobacco media campaigns, increasing access to clinical cessation support, and enforcing restrictions on tobacco advertising and promotion ${ }^{9}$.

\section{Strengths and Limitations}

This is the first study to assess SHS exposure among youths in Nigeria, and may provide data for surveillance of SHS exposure and effectiveness of smoke free policies. However, some limitations exist to this data. First, self-reported SHS exposure may have resulted in an under-reporting of exposure to SHS because of recall bias. However, recall was limited to past 7 days- a relatively short period not likely to result in significant bias. Also, data were not collected on SHS exposure in specified areas, such as in a car, at school, at workplaces, restaurants, or other specific public places. Finally, the data used were not nationally representative, and so generalizations cannot be made to all Nigerian adolescents.

\section{CONCLUSIONS}

This study has shown that a substantial proportion of adolescents in Abuja were exposed to SHS in public places in 2008. Monitoring and evaluation of existing smoke-free policies will provide evidence base for robust tobacco control interventions. Enforcement of existing policies, as well as implementation of stronger, evidence-based measures may help reduce SHS exposure among youths. 


\section{Research Article}

\section{REFERENCES}

1. US Department of Health and Human Services. The health consequences of involuntary exposure to tobacco smoke: a report of the Surgeon General. Atlanta, GA: US Department of Health and Human Services, CDC, \& 2006. Available at: http:// www.surgeongeneral.gov/library/secondhandsmoke/report/ fullreport.pdf. (accessed 30 Oct 2012)

2. Vardavas, C. I., Kondilis, B., Travers, M. J., Petsetaki, E., Tountas, Y., \& Kafatos, A. G. (2007). Environmental tobacco smoke in hospitality venues in greece. BMC Public Health, 7, 302. doi: 10.1186/1471-2458-7-302

3. Ima-Obong Ekanem. (2008). Global youth tobacco survey report for Nigeria 2008 report. Available at: http://www.google. com $/$ url? sa $=\mathrm{t} \& \mathrm{rct}=\mathrm{j} \& \mathrm{q}=\&$ esrc $=\mathrm{s} \&$ source $=$ web $\& \mathrm{~cd}=1 \& \mathrm{cved}=0$ CFgQFjAA\&url=http\%3A\%2F\%2Fwww.afro.who.int\%2Findex. php\%3Foption\%3Dcom_docman\%26task\%3Ddoc_download\%2 6gid\%3D1906\&ei=zkKtT96aM4Tf6QGpidjIDA\&usg=AFQjCN Gs2zRNOfvQCqvtnq-GiRcC9y7wYQ\&sig2=4iVKINN4oKGJ_ YYiSZhc9Q (accessed 3 Nov 2012)

4. Campaign for Tobacco Free Kids. Tobacco Control Laws. Available at: http://www.tobaccocontrollaws.org/legislation/ country/nigeria/laws/desc (accessed 29 Dec 2015)

5. Centers for Disease Control and Prevention. Global HealthNigeria. Tobacco. Available at: http://www.cdc.gov/globalhealth/ countries/nigeria/what/tobacco.htm (accessed 26 March 2013)

6. Punch. Lagos to ban smoking in public places. Available at: http://www.punchng.com/news/lagos-to-ban-smoking-inpublic-places-2/ (accessed 26 March 2013)

7. Vitoria PD, Machado JC, Arajo AC, Ravara SB, Samorinha C, Antunes H, Rosas M, Becoa E, Precioso J. Children's exposure to second hand smoke at home: a cross-sectional study in Portugal. Rev Port Pneumol (2006). 2015 Jul-Aug;21(4):178-84.

8. Agaku, I., Akinyele, A., \& Oluwafemi, A. (2012). Tobacco control in nigeria- policy recommendations. Tobacco Induced Diseases, 10, 8. doi: 10.1186/1617-9625-10-8

9. WHO report on the global tobacco epidemic, 2008-The MPOWER Package. Available at: http://www.who.int/tobacco/mpower/ mpower_report_full_2008.pdf (accessed 23 Sept 2012)

ACKNOWLEDGEMENTS The authors wish to thank Dr. Israel Agaku for his help with the study design, analyses and review of the draft for clarity and accuracy.

\section{CONFLICT OF INTEREST}

The authors have completed and submitted the ICMJE Form for Disclosure of Potential Conflicts of Interest and none were reported.

FUNDING

There was no source of funding for this research.

PROVENANCE AND PEER REVIEW

Not commissioned; externally peer reviewed 